NASA/TM-1998-207921
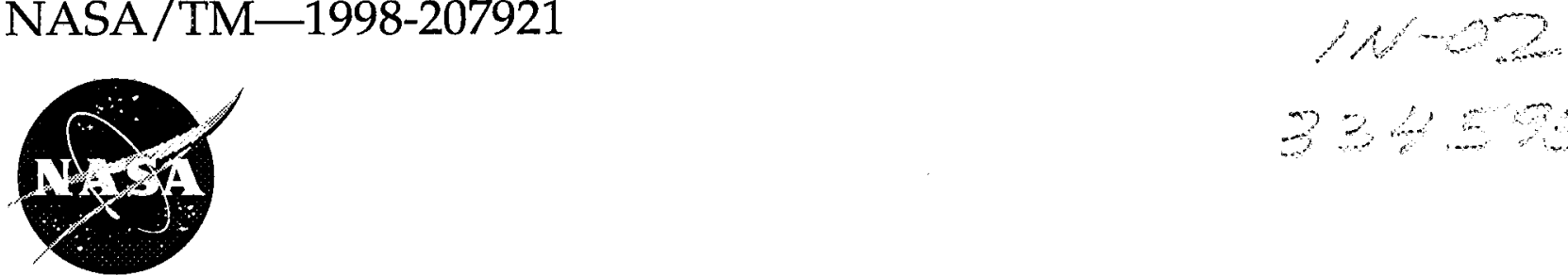

\title{
Experimental Investigation of Boundary Layer Behavior in a Simulated Low Pressure Turbine
}

Ki-Hyeon Sohn

University of Toledo, Toledo, Ohio

Rickey J. Shyne

Lewis Research Center, Cleveland, Ohio

Kenneth J. DeWitt

University of Toledo, Toledo, Ohio

Prepared for the

Turbo Expo 1998

sponsored by the International Gas Turbine Institute of

The American Society of Mechanical Engineers

Stockholm, Sweden, June 2-5, 1998

National Aeronautics and

Space Administration

Lewis Research Center 
Available from

NASA Center for Aerospace Information 7121 Standard Drive

Hanover, MD 21076

Price Code: A03
National Technical Information Service 5287 Port Royal Road Springfield, VA 22100 Price Code: $\mathrm{A} 03$ 


\title{
EXPERIMENTAL INVESTIGATION OF BOUNDARY LAYER BEHAVIOR IN A SIMULATED LOW PRESSURE TURBINE
}

\author{
Ki H. Sohn \\ University of Toledo \\ Toledo, Ohio 43606
}

\author{
Rickey J. Shyne \\ NASA Lewis Research Center \\ Cleveland, Ohio 44135
}

\author{
Kenneth J. DeWitt \\ University of Toledo \\ Toledo, Ohio 43606
}

\begin{abstract}
A detailed investigation of the flow physics occurring on the suction side of a simulated Low Pressure Turbine (LPT) blade was performed. A contoured upper wall was designed to simulate the pressure distribution of an actual LPT blade onto a flat plate. The experiments were carried out at Reynolds numbers of 100,000 and 250,000 with three levels of freestream turbulence. The main emphasis in this paper is placed on flow field surveys performed at a Reynolds number of 100,000 with levels of freestream turbulence ranging from $0.8 \%$ to $3 \%$. Smoke-wire flow visualization data was used to confirm that the boundary layer was separated and formed a bubble. The transition process over the separated flow region is observed to be similar to a laminar free shear layer flow with the formation of a large coherent eddy structure. For each condition, the locations defining the separation bubble were determined by careful examination of pressure and mean velocity profile data. Transition onset location and length determined from intermittency profiles decrease as freestream turbulence levels increase. Additionally, the length and height of the laminar separation bubbles were observed to be inversely proportional to the levels of freestream turbulence.
\end{abstract}

\section{NOMENCLATURE}

$\mathrm{C}_{\mathrm{P}} \quad$ Static pressure coefficient $\left.\left[=2\left(\mathrm{P}-\mathrm{P}_{\text {exit }}\right) / \mathrm{\rho U}^{2}{ }_{\text {exit }}\right)\right]$

E Hot-film gage voltage, volts

$\mathrm{H} \quad$ Bubble height, $\mathrm{cm}$

L Effective working plate length, $\mathrm{cm}$

$\overline{\mathrm{P}} \quad$ Gaster's pressure parameter $\left[=\left(\theta_{\mathrm{s}}{ }^{2} / \mathrm{v}\right)(\Delta \mathrm{U} / \Delta \mathrm{x})\right]$

$\mathrm{Re} \quad$ Test section Reynolds number $\left[=\mathrm{U}_{\text {exit }} \mathrm{L} / \mathrm{v}\right]$

$\operatorname{Re}_{L_{T}} \quad$ Transition length Reynolds number

$\operatorname{Re}_{\theta_{\mathrm{s}}} \quad$ Momentum thickness Reynolds number at separation $\left[=\mathrm{U}_{\mathrm{s}} \boldsymbol{\theta}_{\mathrm{s}} / \mathrm{v}\right]$

Tu Local freestream turbulence level

$\mathrm{U} \quad$ Axial mean velocity, $\mathrm{m} / \mathrm{sec}$

$\mathrm{u}_{\mathrm{rms}}^{\prime} \quad$ Axial fluctuating velocity, $\mathrm{m} / \mathrm{sec}$

\author{
$\mathrm{X}, \mathrm{x} \quad$ Axial distance from leading edge, $\mathrm{cm}$ \\ $y \quad$ Normal distance from surface, $\mathrm{cm}$

\section{Greek} \\ $\delta \quad$ Boundary layer thickness at $\mathrm{U} / \mathrm{U}_{\mathrm{e}}=0.995, \mathrm{~cm}$ \\ $\theta$ Momentum thickness, $\mathrm{cm}$ \\ $\Gamma \quad$ Intermittency \\ $\Lambda \quad$ Longitudinal integral length scale, $\mathrm{cm}$ \\ $\psi_{\mathrm{i}} \quad$ Stream function $\left[=\int_{0}^{y_{i}}\left(\mathrm{U} / \mathrm{U}_{\text {ref }}\right) \mathrm{dy}\right]$ \\ $v \quad$ Kinematic viscosity, $\mathrm{m}^{2} / \mathrm{sec}$

\section{Subscripts}

\begin{tabular}{ll}
\hline B & Bubble \\
e & Edge of boundary layer \\
$\mathrm{R}$ & Reattachment \\
ref & Reference \\
$\mathrm{S}$ & Separation \\
$\mathrm{T}$ & Transition
\end{tabular}

\section{INTRODUCTION}

Gas turbine engine designers are constantly seeking ways to improve engine efficiency. The engine performance at cruise conditions, especially the behavior of engine components such as the low pressure turbine (LPT), is less clear due to limitations of ground test facilities to model altitude flight conditions. Many factors are known to influence the performance of the LPT, but factors such as blade loading, end wall losses, wake passing effects and boundary layer separation and/or transition play a major role. The accurate prediction of the separation and transition processes on LPT blades under the influence of adverse pressure gradients, altitude Reynolds numbers and various freestream turbulence levels can lead directly to improved engine efficiency and lower specific fuel consumption. The primary objective of this experimental study is to determine whether 
the boundary layer flow on the suction side of a simulated LPT blade undergoes separation under cruise type flight conditions independent of wake passing, curvature or endwall effects. Additionally, if separation does occur, it is desired to characterize the separation bubble. This characterization is required because the chordwise extent of a separation bubble at high freestream turbulence and low Reynolds number is not large enough to alter the global flow pattern. However, a significant problem exists in defining an initial boundary condition for calculating the turbulent boundary layer at the downstream end of the bubble.

Gardner (1981) performed experimental studies on the effect of loading on LPT blades. The results showed that when designed properly, highly loaded blades exhibit higher performance than blades designed with a lower loading profile. Because of this study and others, modern LPT blades are now designed to be more highly loaded with lower aspect ratios that introduce highly adverse as well as highly favorable pressure gradients into the flow field. Halstead et al. (1995) performed an experimental study of boundary layer development on the suction surface of airfoils in an embedded stage of a LPT. This study revealed substantial regions of laminar and transitional flow on the suction surface, but no flow separation was apparent. This study also showed that the calmed regions, generated by the turbulent spots produced in the wake paths, were effective in suppressing the flow separation. Morin \& Patrick (1991) performed a detailed study of a large scale laminar separation bubble on a flat plate. It was determined from this experiment that the reattachment location of a short bubble was time dependent. Since the boundary layer approaches steady state very slowly, conventional eddy-viscosity models for the turbulent boundary layer were not valid until far downstream from the reattachment location. A fully turbulent boundary layer was not achieved even after 200 bubble heights downstream from the reattachment location. It can be deduced from these experimental studies that even a short bubble can play a critical role in defining the initial boundary condition for the turbulent boundary layer calculation.

The present experimental study was conducted on a simulated LPT blade test section. The differences in the transition processes between the separated and attached boundary layers were studied qualitatively and quantitatively. Flow visualization, pressure, mean and fluctuating velocities and instantaneous hot-film data are used to analyze the flow-field simulated in this experiment.

\section{EXPERIMENTAL FACILITY}

The experiments were performed in a low-speed, closed-loop wind tunnel located at the NASA Lewis Research Center. This wind tunnel was designed to generate large scale, two dimensional, incompressible boundary layers. The test section freestream turbulence levels can be changed by the use of turbulence generating grids. A detailed description of the tunnel components can be found in Suder et al. (1988).

A contoured upper wall was designed to generate a pressure distribution on the bottom flat test surface which matches the pressure gradient generated by the suction surface of a generic LPT blade. In order to properly match the Reynolds number in a full scale LPT, a splitter plate was inserted in the middle of the test section to bifurcate the test section flow. The schematic of the test section is shown in Fig. 1. The splitter plate, which also doubled as the test flat plate, has a 4:1 elliptical leading edge and a trailing deflector which forces the stagnation point to fall on top of the working surface at the leading edge by generating circulation. The test plate was instrumented with fourteen flush-mounted hot-film gages located at $1.27 \mathrm{~cm}$. intervals along the centerline and eighteen static pressure taps located one inch off of the plate centerline.

This generic LPT blade geometry was supplied by an engine company. The test section design was created by matching the mass flow from the generic LPT blade cascade through a flow channel with a contoured upper wall and a flat lower wall. An inviscid panel code developed by McFarland (1982) was used to compute the blade velocity and pressure distribution. The flow field data computed by the panel code are functions of the area change throughout the channel. One and two body options were used in the panel code to generate the upper wall and the continuity equation was utilized to account for the difference between the two options. Details of this procedure can be found in Shyne \& DeWitt (1998).

The test section contour was then analyzed using the NPARC full Navier-Stokes computational code, NPARC Alliance (1994). This analysis of the test section contour was performed to validate the effect of the contoured upper wall. The NPARC analysis did reveal a separated flow region just downstream of the maximum thickness on the contoured upper wall. An upper wall bleed suction system was added to alleviate this problem and help generate the proper pressure distribution on the flat plate test surface.

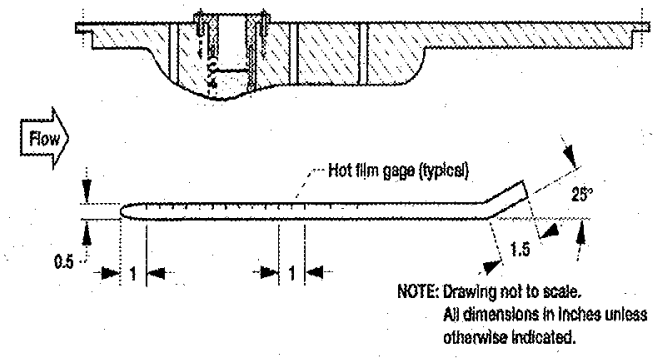

Figure 1. Schematic of simulated test section (1 in. $=2.54 \mathrm{~cm}$.)

\section{EXPERIMENTAL RESULTS}

Detailed flow field measurements were obtained over the entire flat plate for both accelerating and decelerating flow regions at Reynolds numbers of 100,000 and 250,000 with various levels of freestream turbulence. The Reynolds number is based upon effective working plate length of $15.50 \mathrm{~cm}$. and exit freestream velocity. The primary emphasis of this paper is placed on flow field surveys in the adverse pressure gradient region at a Reynolds number of 100,000 with three nominal freestream turbulence levels of $0.8 \%$ (grid 0 ), $2 \%$ (grid 2) and 3\% (grid 3). The profiles were obtained at ten measurement stations ranging from $x=12.07 \mathrm{~cm}$. to $x=23.50 \mathrm{~cm}$. from the leading edge of the flat plate in increments of $1.27 \mathrm{~cm}$.

\section{Flow Visualization}

Smoke wire flow visualization was conducted to capture the qualitative features of the flow. This flow visualization was performed with grid 0 at a Reynolds number of 50,000 (based on an exit velocity of $4.92 \mathrm{~m} / \mathrm{s}$ ), which is lower than the typical cruise Reynolds number. Three instantaneous photographs of flow visualization are shown in Fig. 2 and show the presence of a laminar separation bubble. Due to rapid dispersion of the smoke at higher Reynolds numbers and intense 
mixing with higher turbulence levels, good quality photographs could not be obtained for higher Reynolds numbers and higher turbulence conditions. No smoke is present in the region between the separated shear layer and the test surface within the front part of the separation bubble due to infinitesimal viscous shear stresses. The flow fields in this so-called 'dead-air' region look similar in each photograph, which indicates that the laminar region of the separation bubble is steady. However, a difference in the flow pattern in the region downstream of the maximum bubble height reveals that the transition and the reattachment processes are unsteady. A large eddy structure is apparent in the photographs downstream from the maximum bubble height in the shear layer. These eddies eventually become unstable and, through interaction with each other, finally develop into a turbulent boundary layer. This transition process is similar in behavior to a laminar free shear layer flow, where discrete spanwise vortices form due to the Kelvin-Helmholtz instability and eventually break down into a fully turbulent shear layer. A detailed flow visualization study performed by Morin and Patrick (1991) also revealed this eddy formation in the shear layer.
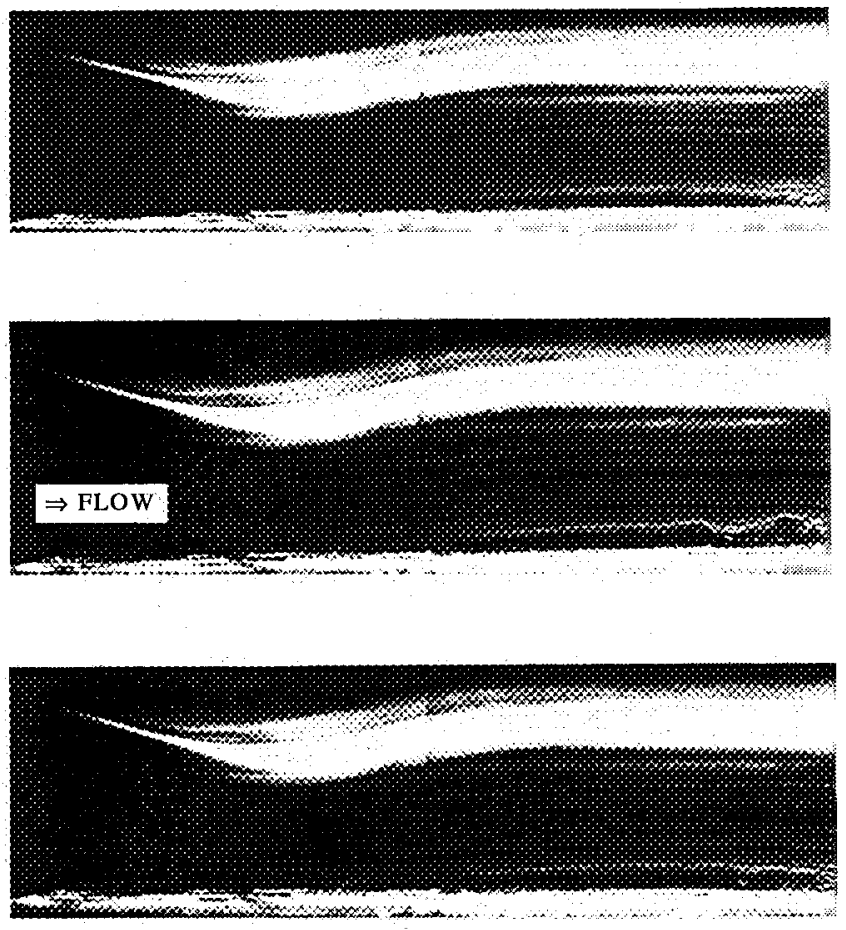

\section{Figure 2. Smoke-wire flow visualization of separation bubble, Grid $0, \mathrm{Re}=\mathbf{5 0 , 0 0 0}$}

\section{Streamwise Pressure Distributions}

Static pressure distributions were obtained on the surface of the flat plate at three levels of freestream turbulence. The variation of pressure coefficient, $C_{p}$, based on exit static and total pressures for a Reynolds number of 100,000 is presented in Fig. 3. The flow is accelerated up to the suction peak in the converging section and then is decelerated by the adverse pressure gradient. If the adverse pressure gradient is sufficient, the laminar boundary layer reaches separation before transition is achieved. As shown in Fig. 3, after the suction peak, the pressure increases steadily and then reaches a nearly constant level because of negligible turbulent diffusion in the laminar part of the separated flow region. This constant pressure plateau is identified as the dead-air region in the flow visualization. Downstream from the constant pressure region the pressure rises sharply for a short distance to a certain point, then slowly increases to the exit pressure level. The shape of the mean dividing streamline can be determined by this pressure distribution. The separation bubble identified in the flow. visualization and pressure distribution data can be seen as a small perturbation of the inviscid flow such that a constant pressure region rises under the laminar shear layer.

For each freestream turbulence level tested, the beginning of the constant pressure region is nearly identical, within experimental error, indicating that the freestream turbulence level has little or no effect on the separation location. However, with increasing freestream turbulence level, the extent of the constant pressure region progressively shrinks and the downstream end of the sudden pressure rise (reattachment location) moves upstream, indicating the overall bubble length has decreased.

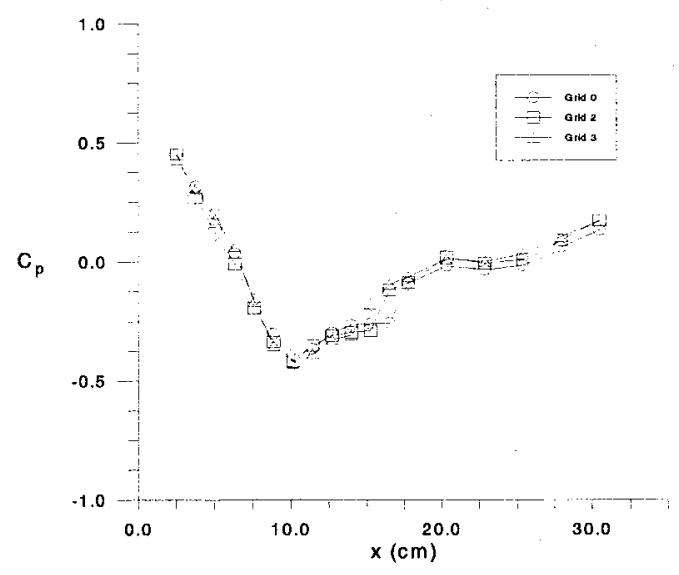

Figure 3. Pressure distribution on the test plate. $(R e=100,000)$

\section{Hot-film Voltage Traces}

A series of flush-mounted hot-film gages were used to identify the transition process. The typical instantaneous hot-film voltage traces for grid 2 and Reynolds numbers of 100,000 and 250,000 are shown in figs. 4a-b. A typical stable laminar boundary layer signal can be seen in the first voltage trace at $x=12.70 \mathrm{~cm}$. A steady signal is obvious in the second voltage trace at $x=13.97 \mathrm{~cm}$. in Fig. 4 a because it is in the laminar portion of the separation bubble (refer to Table 1 for the streamwise location of bubble). An oscillating signal with high frequency components is shown in the third voltage trace and grows rapidly through the transition and reattachment region $(x=15.24$ and $17.78 \mathrm{~cm}$.). The signals at these locations eventually become more random in character and finally develop into a fully turbulent signal.

Figure $4 \mathrm{~b}$ shows the series of hot-film traces for a Reynolds number of 250,000. Due to increased Reynolds number, the transition location moves upstream of the point where laminar separation would occur. Consequently, the increased wall shear stress resulting from the boundary layer transition keeps the boundary layer from separating at this Reynolds number. In Fig. 4b, intermittent turbulent spots can be clearly seen in the second trace at $x=13.97 \mathrm{~cm}$. These turbulent spots 
are formed more frequently as the flow proceeds downstream (from $\mathrm{x}=13.97 \mathrm{~cm}$. to $\mathrm{x}=17.78 \mathrm{~cm}$.), finally merging together and becoming a fully turbulent flow. It can be seen from the hot-film traces in Fig. 4b that transition is initiated between $x=12.70-13.97 \mathrm{~cm}$., where the boundary layer separates for a Reynolds number of 100,000 (Fig. 4a). This transition process follows the typical path for an attached boundary layer through the formation of turbulent spots.

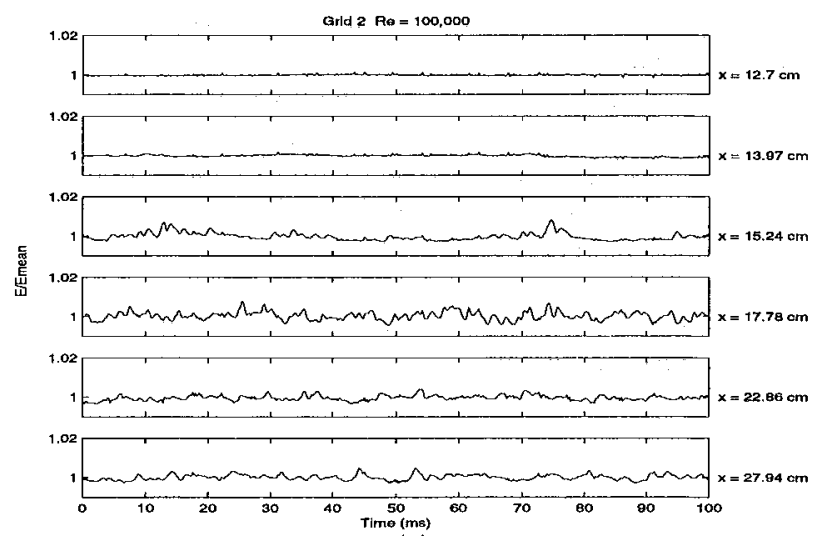

(a)

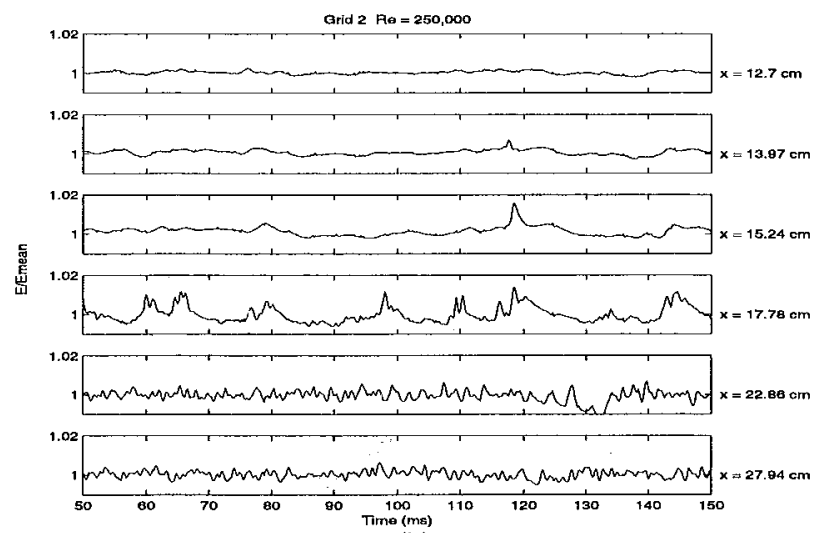

(b)

Figures 4a-b. Flush-mounted hot-film signals for Grid 2 $R e=100,000(a)$ and $R e=250,000(b)$

\section{Mean Velocity Profiles}

To further investigate this complex flow field at a Reynolds number of 100,000 , streamwise mean and fluctuating velocity profiles were measured with a single hot-wire probe. Figures $5 \mathrm{a}-\mathrm{c}$ present the variation of the mean velocity profile normalized with the freestream velocity at the first measurement station under the adverse pressure gradient $\left(x=12.07 \mathrm{~cm}\right.$. ) for each condition. The stream function, $\psi_{i}$ was determined by integrating the mean velocity at any point $y_{i}$ up to the vicinity of the upper wall, which is $\psi_{i}=\int_{0}^{y_{i}} U / U_{\text {ref }} d y$. Equal values of $\psi_{i}$ used to define the streamline patterns are also shown in figs. 5a-c for each condition. The profile at the first measurement station has an inflection point imposed by the adverse pressure gradient (at $\mathrm{x}=12.07 \mathrm{~cm}$.), which is the precursor of boundary layer separation. A small hump in the streakline patterns downstream of the first measurement station was detected for each condition. Due to the inability of the hot-wire to determine the flow direction, no reverse flow could be detected. Instead, nearly constant velocity profiles were measured near the test surface which indicates a separated flow region. The laminar shear layer outside of the front

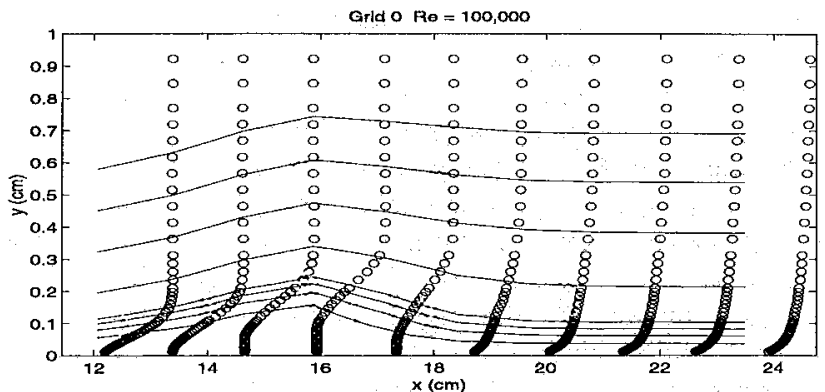

(a)

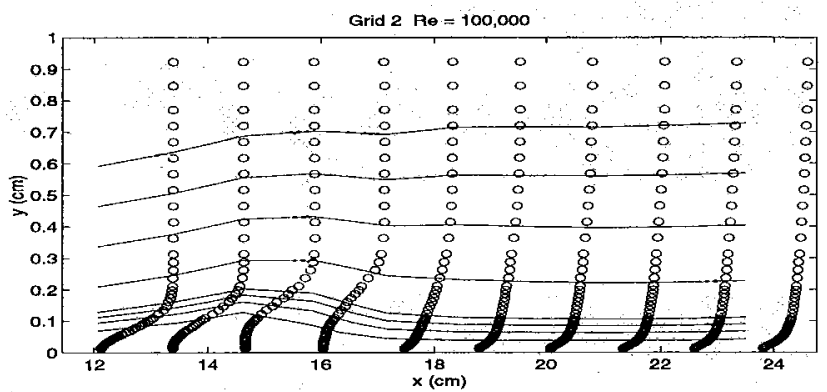

(b)

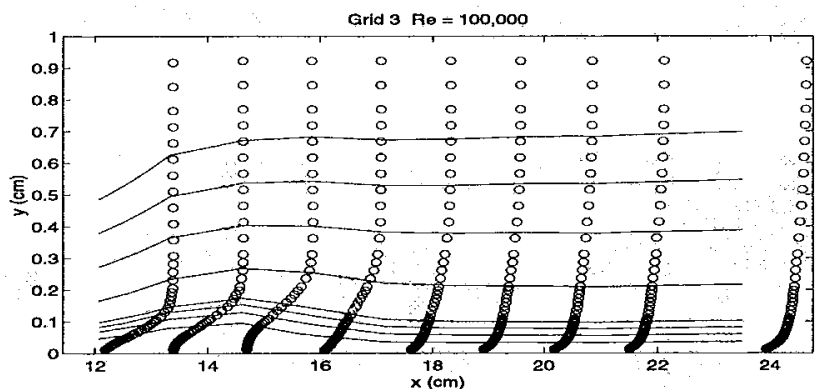

(c)

Figure 5a-c. Distribution of $\mathrm{U} / \mathrm{U}_{\text {ref }}$ for Grids 0,2 and 3 $R e=100,000\left(U_{\text {ref }}=U_{e}\right.$ at $\left.X=12.07 \mathrm{~cm}.\right)$

part of the bubble (dead-air region) is usually characterized by a nearly constant velocity gradient. The maximum bubble height was determined by interpolating the extent of this constant velocity region and is listed in Table 1 for each condition. It can be noted that the bubble length and height are all inversely proportional to the freestream turbulence level. The uncertainty in the hot-wire measurements was determined to be $1.45 \%$ for the mean and fluctuating velocity components using methods developed by Yavuzkurt (1984). 
The flow near the lower wall is distorted by the bubble. The velocity profile just downstream of the bubble $(x=17.78 \mathrm{~cm}$. ) shows double inflection points and finally develops into a fully attached turbulent boundary layer further downstream. Generally, these short bubbles only alter the local flow field, not affecting the global flow pattern away from the wall.

The contour plot of constant mean velocity for grid 0 is shown in Fig. 6. The general shape of the bubble can be determined from this contour plot. The velocity gradient is nearly constant in the separated laminar shear layer just outside the front part of the bubble, indicating that the flow is not expanding. The bubble has a shallow triangular dead-air region and a rather steep closing area due to high turbulent diffusion. At the end of the dead-air region, the profiles show a sudden increase in the magnitude of velocity near the wall. The velocity gradient decreases to a minimum value at the reattachment location and then increases to a turbulent value farther downstream. The velocity gradient at or near the reattachment location should be zero since skin friction is ideally zero, but because of the limitations of the hot-wire, a small velocity gradient was measured. The contour plots for grids 2 and 3 exhibit the same trends as that for grid 0 , except for a smaller bubble size.

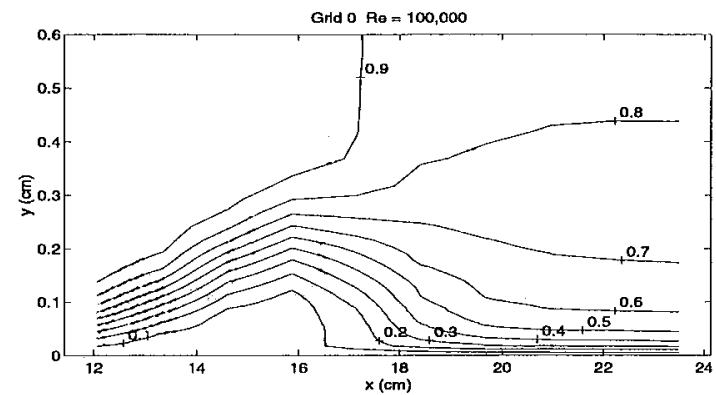

\section{Figure 6. Contour plot of $\mathrm{U} / \mathrm{U}_{\text {ret }}$ Grid $0, \mathrm{Re}=100,000$ $\left(U_{\text {ref }}=U_{e}\right.$ at $\left.X=12.07 \mathrm{~cm}.\right)$}

\section{Intermittency Profiles}

Intermittency profiles were also computed from the digitally recorded mean velocity profile data and are shown in Figs. 7a-c. Intermittency, $\Gamma$, is defined as the fraction of time during which the flow at a given position remains turbulent after the onset of transition. A flow is considered fully turbulent if $\Gamma=1$ and fully laminar if $\Gamma=0$. The instantaneous velocity signal was segregated into turbulent and non-turbulent parts based on both of the squares of the first and second derivatives of the signals. The detailed technique can be found in the papers by Sohn \& Reshotko (1991) and Shyne \& DeWitt (1998). Figure 7a is an intermittency profile plot for grid 0 and it shows that transition begins between $x=14.07$ and $x=15.88 \mathrm{~cm}$. A peak intermittency value occurs for $x=15.88 \mathrm{~cm}$. at an approximate $y / \delta$ value of 0.5 . As the flow proceeds downstream in the test section, the peak intermittency values move towards the wall with the flow becoming fully turbulent. Figures $7 \mathrm{~b}$ and $\mathrm{c}$ are the intermittency profile plots for grids 2 and 3 . These plots exhibit similar trends to the grid 0 intermittency plot, but the transition point moves upstream and the transition length decreases. This transition process occurs in the shear layer which bounds the freestream flow and bubble surface.

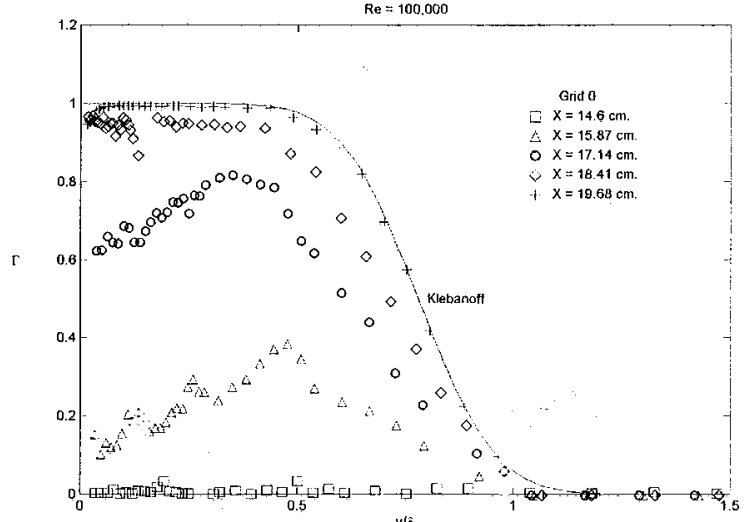

(a)

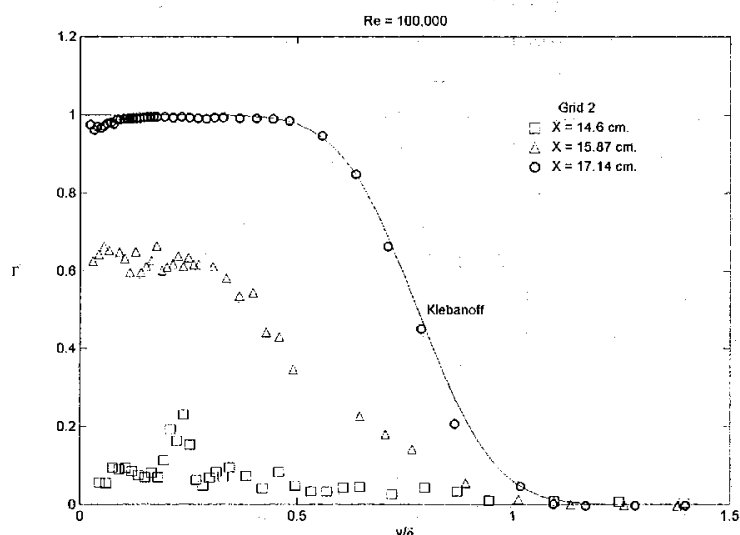

(b)

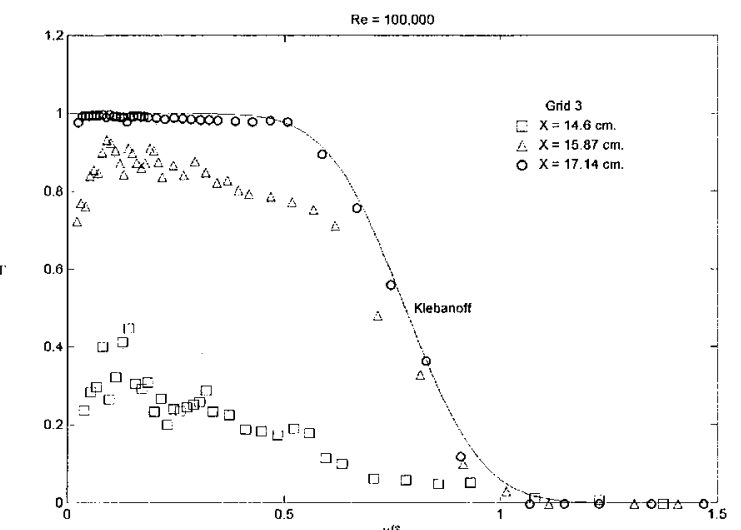

(c)

Figure 7a-c. Intermittency profiles $\mathrm{Re}=100,000$ Grid 0 (a), Grid 2 (b) and Grid 3 (c)

Additionally, the flat portions of the intermittency profiles for $y / \delta$ values less than 0.2 for each condition correspond to the constant velocity region inside the separation bubble. Shear flow transition starts at approximately $x=14.07 \mathrm{~cm}$. for grid 2 and before $x=14.07 \mathrm{~cm}$. for grid 3, respectively. Peak intermittency values occur for grid 2 at $x=14.07 \mathrm{~cm}$. at a $y / \delta$ value of approximately 0.25 . Fully turbulent flow occurs at approximately $x=17.15 \mathrm{~cm}$. for grid 2 and at approximately $x=15.88-17.15 \mathrm{~cm}$. for grid 3 . Approximate transition 
onset and fully turbulent flow locations obtained from the intermittency profiles agree favorably with those deduced from the hot-film data for each condition. Locations of transition onset and transition lengths for each condition are listed in Table 1.

\section{RMS Velocity Profiles}

The fluctuating rms velocity profiles are shown in Fig. 8 for grid 0 along with the same streamline patterns plotted for the mean velocity profiles in Fig. 5a. In the laminar boundary layer at a low freestream turbulence level (grid 0), the rms velocity profile shows nearly a flat profile with small magnitudes for the entire flow field except for a small hump near the wall. This small first peak grows in magnitude and moves away from the wall to the shear layer as the flow goes downstream from the separation location. This peak in the shear layer grows rapidly after the maximum bubble height location and triggers a slowdown of bubble growth due to turbulent energy dispersion. Another hint of the small peak is noticed inside the bubble at $x=15.88$ $\mathrm{cm}$. Due to limited measurement stations within the separation bubble and the inability of the hot-wire to correctly measure velocity profiles in the reverse flow region, the peak that developed inside the bubble could not be studied. However, in the LDV experiment on the diverging channel flow performed by Morin and Patrick (1991), it was observed that the second peak which developed inside the bubble substantially outgrew the first peak and they merged together further downstream. They also found that a third peak developed around the edge of the boundary layer. For higher freestream turbulence levels (grids 2 and 3), the peak is much larger than that for grid 0 at the first measurement station because the laminar boundary layer is buffeted by higher freestream turbulence. Note that the fluctuating velocity profiles measured at the last measurement station $(x=23.50 \mathrm{~cm}$.) are

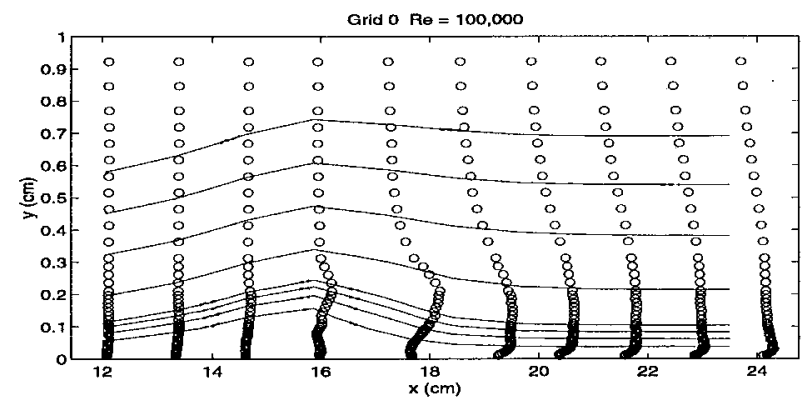

\section{Figure 8. Distribution of $u_{\text {rms }}^{\prime} / U_{\text {ref }}$ Grid $0, R e=100,000$ $\left(U_{\text {ref }}=U_{e}\right.$ at $x=12.07 \mathrm{~cm}$.)}

different from that of the equilibrium turbulent boundary layer suggested by Klebanoff (1955) for each condition, which indicates that even though an attached turbulent boundary layer profile was measured at $x=23.50 \mathrm{~cm}$., the nature of the boundary layer is different due to the upstream bubble.

\section{Classification of Separation Bubble}

Gaster (1969) proposed a two parameter bubble criterion using a relationship between momentum Reynolds number at separation $\operatorname{Re}_{\theta_{s}}$, and pressure parameter $\overline{\mathrm{P}}=\left(\theta_{\mathrm{s}}{ }^{2} / v\right)(\Delta \mathrm{U} / \Delta \mathrm{x})$, based on his two sets of airfoil data and other researchers' experimental and calculated data.
The pressure parameter, $\Delta \mathrm{U}$, is the rise in freestream velocity that would occur over the bubble length, $\Delta x$, in an unseparated inviscid flow since the bubble shape is dependent on the pressure distribution that would rise without separation. Gaster's two parameter bursting criterion with pressure parameters measured in the present experiments are plotted in Fig. 9. Three domains are defined in this figure. For $\overline{\mathbf{P}}$ $<-0.09$, the flow will not separate at all Reynolds numbers. To the right of the bursting boundary, a short bubble will be formed, and to the left, a long (bursting) bubble will develop. It is clear that the bubbles formed in the present experiment are all short ones. In the present experiment, the inviscid pressure and $\Delta \mathrm{U}$ are estimated from the Reynolds number of 250,000 at which the boundary layers are attached for the entire test section.

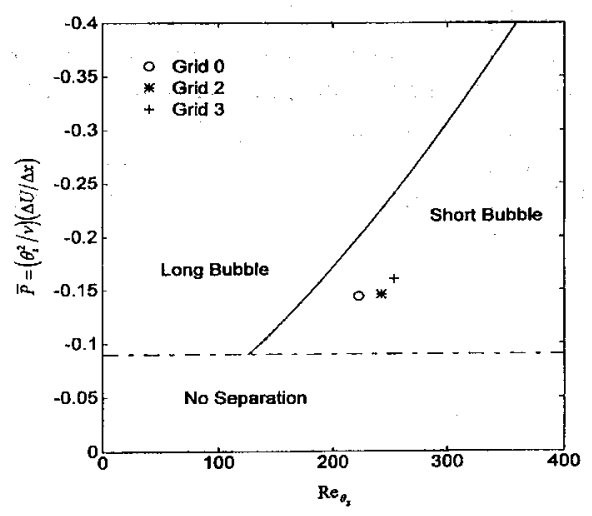

Figure 9. Gaster's two parameter bubble criteria

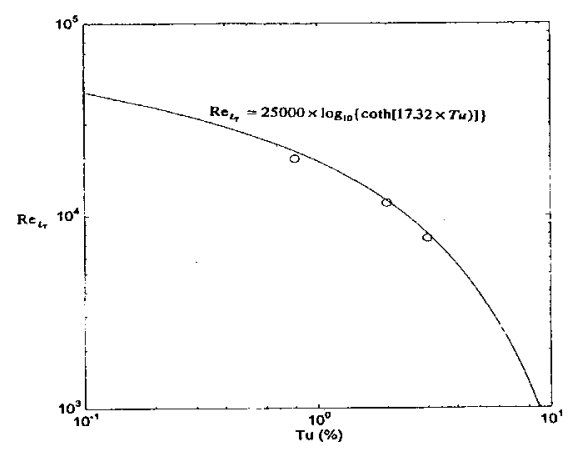

\section{Figure 10. Comparison of variation of transition length Reynolds number with freestream turbulence levels}

Several empirical correlations have been developed accounting for the effects of freestream turbulence on the separation bubble length. Roberts (1980) related the transition length of the separation bubble to the turbulence scale factor, in which the turbulence scale is involved. The turbulence scale is a quantity not easily obtainable in experiments. Davis et al. (1985) modified the Roberts' correlation to replace the freestream turbulence factor with the local freestream turbulence level, i.e., $\left.\operatorname{Re}_{L_{T}}=25000 \times \log _{10}\{\operatorname{coth}[17.32 \times T u)]\right\}$.

The variation of transition length Reynolds number at separation along with Roberts' modified correlation is presented in Fig. 10. The transition region determined from the intermittency profiles for each 
freestream turbulence level shows excellent agreement with this empirical correlation.

\section{Power Spectra}

Spectral analysis data was also taken to help understand the character and nature of the disturbances in the boundary layer and freestream regions of the flow field. Figure 11 shows the power spectral density (PSD) plot at the maximum rms position for grid 0 and a Reynolds number of 100,000 . Spectral data was obtained at a sampling rate of $12.8 \mathrm{kHz}$. using the average of 100 scans. This data shows that almost all of the fluctuating energy is confined in low frequencies less than $700 \mathrm{~Hz}$. at $\mathrm{x}=12.07$ and $13.34 \mathrm{~cm}$., resembling a laminar flow-field spectra. The flow field was contaminated by main and bleed blowers noise and their sub-harmonics. A two-order of PSD magnitude jump occurs at $x=14.07 \mathrm{~cm}$. for low frequencies less than $1200 \mathrm{~Hz}$. followed by a larger jump in the spectra for all frequency bands measured at $x=15.88-17.15 \mathrm{~cm}$. This small jump around $\mathrm{x}=$ $14.07 \mathrm{~cm}$. indicates transition onset and the spectra increases in magnitude as the flow becomes fully turbulent as it moves downstream. This behavior agrees with the intermittency profile for grid 0 as shown in Fig. 7a. The PSD spectra over the separation bubble shows no broad band disturbance hump around $1500 \mathrm{~Hz}$, which would be caused by a Kelvin-Helmholtz type instability in the flow field. Additionally, the approximate locations of transition onset and fully turbulent flow deduced from the PSD agree favorably with those deduced from the intermittency profiles.

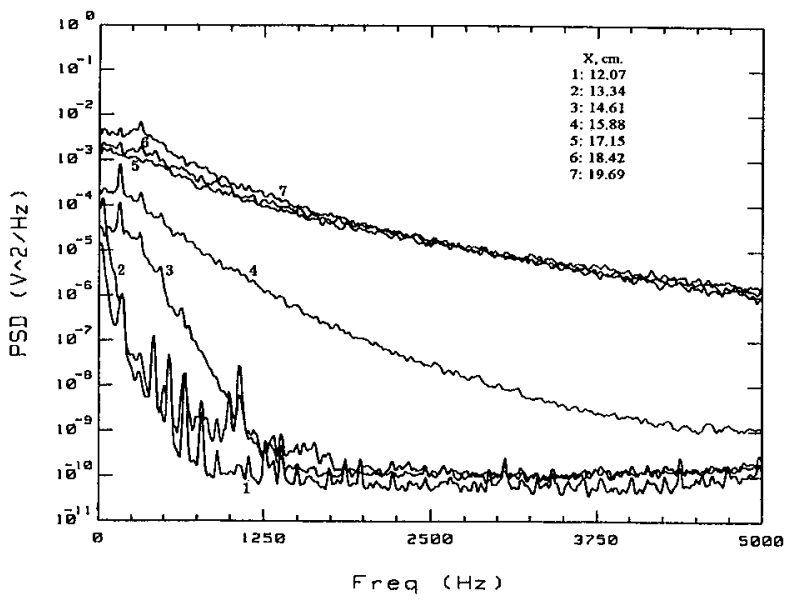

Figure 11. Boundary layer spectra, $y=y\left(u_{\max }^{\prime}\right)$ (Grid 0, Re $=100,000$ )

The longitudinal integral length scales computed from the power spectral density data is summarized in Table 2 . The integral length scale increases as the turbulence level increases and this is consistent for both Reynolds numbers tested.

\section{CONCLUSIONS}

The parametric investigation of the flow field on a simulated LPT blade was performed at three levels of freestream turbulence for a Reynolds number of 100,000 . The flow visualization data confirmed that the boundary layer was separated and formed a bubble. Based on a two parameter bubble bursting criterion proposed by Gaster (1969), the bubbles formed in these experiments were short, non-bursting bubbles.

Flow visualization photographs revealed that the laminar portion of the bubble is steady, while the region downstream from transition are unsteady. The transition process over the separated flow regions for a Reynolds number of 100,000 is similar to a laminar free shear layer through the formation of a large coherent eddy structure. However, the transition path for an attached boundary layer is through the formation of intermittent turbulent spots. These two distinct transition mechanisms were confirmed by a series of instantaneous hot-film signals. The pressure distribution shows a typical feature, namely a nearly constant pressure zone followed by a sharp pressure rise region. Intermittency profiles showed that shear flow transition initiated between $x=14.07$ and $15.88 \mathrm{~cm}$. for grid 0 , at approximately $x=14.07 \mathrm{~cm}$. for grid 2 , and before $x=14.07 \mathrm{~cm}$. for grid 3 .

Additionally, the intermittency profiles revealed that fully turbulent flow occurs approximately at $x=18.42-19.69 \mathrm{~cm}$. for grid 0 , at $x=17.15 \mathrm{~cm}$. for grid 2, and between $x=15.88-17.15 \mathrm{~cm}$. for grid 3 . The transition onset location and length are inversely proportional to the freestream turbulence level. Additionally, the characteristics of transition deduced from the intermittency profiles and boundary layer spectra data show excellent agreement. The modified Roberts' transition length correlation predicts quite well the transition length of the bubble for each condition. It was also observed that bubble length and height decreased as freestream turbulence level increased.

Additional experimental work is currently being conducted at lower Reynolds numbers and various freestream turbulence levels to identify the conditions at which the separation bubble may burst.

\section{REFERENCES}

Davis, R. L., Carter, J. E., and Reshotko, E., 1985, “Analysis of Transitional Separation Bubbles on Infinite Swept Wings," AIAA-851685.

Gardner, W. B., 1981, "Energy Efficient Engine Low Pressure Turbine Boundary Layer Program Technology Report," NASA CR165338.

Gaster, M., 1969, "The Structure and Behavior of Laminar Separation Bubbles," A.R.C. R\&M 3595.

Halstead, D. E., Wisler, D. C., Okiishi, T. H., Walker, G. J., Hodson, H. P., and Shin, H., 1995, "Boundary Layer Development in Axial Compressors and Turbines, Part 3 of 4: LP Turbines," ASME Paper 95-GT-463.

Klebanoff, P.S. 1955, "Characteristics of Turbulence in a Boundary Layer with Zero Pressure Gradient," NACA Rep. No. 1247.

McFarland, E. R., 1982, "Solution of Plane Cascade Flow Using Improved Surface Singularity Methods," Journal of Engineering for Power, Vol.104, pp. 668-674.

Morin, B. L., and Patrick, W. P., 1991, "Detailed Studies of a Large-Scale Laminar Separation Bubble on a Flat Plate: Volume 1 Experimental Technique, Summarized Results, and Discussion," UTRC Rep. R91-956786-1.

NPARC Alliance Technical Team, 1994, NASA Lewis Research Center and Arnold Engineering Development Center, “A User's Guide to NPARC", Version 2.0.

Roberts, W. B., 1980, "Calculation of Laminar Separation Bubbles and Their Effect on Airfoil Performance", AIAA J., Vol. 18, No. 1, pp. 25-30. 
Shyne, R. J. and DeWitt, K. J., 1998, "Experimental Study of Boundary Layer Behavior in a Simulated Low Pressure Turbine," Ph.D. Dissertation in progress, University of Toledo.

Sohn, K. H. and Reshotko, E., 1991, "Experimental Study of Boundary Layer Transition with Elevated Freestream Turbulence on a Heated Flat Plate," NASA CR-187068.
Suder, K. L., O’Brien, J. E., and Reshotko, E., 1988, "Experimental Study of Bypass Transition in a Boundary Layer," NASA TM-100913.

Yavuzkurt, S., "A Guide to Uncertainty Analysis of Hot-Wire Data", Journal of Fluids Engineering, Vol. 106, June 1984, pp. 181186.

Table 1. Separation bubble characteristics

\begin{tabular}{|c|c|c|c|c|c|c|}
\hline & $\mathrm{X}_{s}(\mathrm{~cm})$. & $\mathrm{X}_{\mathrm{I}}(\mathrm{cm})$. & $\mathrm{X}_{\mathrm{R}}(\mathrm{cm})$. & $\mathrm{L}_{\mathrm{R}}(\mathrm{cm})$. & $\mathrm{L}_{\mathrm{I}}(\mathrm{cm})$. & $H_{\mathrm{B}}(\mathrm{cm})$. \\
\hline Grid 0 & $\approx 13.30$ & $\approx 14.75$ & $\approx 17.50$ & $\approx 4.20$ & $\approx 2.70$ & $\approx 0.110$ \\
\hline Grid 2 & $\approx 13.30$ & $\approx 14.54$ & $\approx 16.00$ & $\approx 2.70$ & $\approx 1.77$ & $\approx 0.056$ \\
\hline Grid 3 & $\approx 13.30$ & $\approx 14.40$ & $\approx 14.94$ & $\approx 1.65$ & $\approx 1.52$ & $\approx 0.030$ \\
\hline
\end{tabular}

Table 2. Longitudinal integral length scale (cm.)

\begin{tabular}{|c|c|c|c|}
\hline & Grid 0 & Grid 2 & Grid 3 \\
\hline $\operatorname{Re}=100,000$ & 0.53 & 1.58 & 3.04 \\
\hline $\operatorname{Re}=250,000$ & 0.85 & 1.88 & 3.40 \\
\hline
\end{tabular}


Public reporting burden for this collection of information is estimated to average 1 hour per response, including the time for reviewing Instructions, searching existing data sources, gathering and maintaining the data needed, and completing and reviewing the collection of information. Send comments regarding this burden estimate or any other aspect of this collection of information, including suggestions for reducing this burden, to Washington Headquarters Services, Directorate for Information Operations and Reports, 1215 Jefferson Davis Highway, Suite 1204, Arlington, VA 22202-4302, and to the Office of Management and Budget, Paperwork Reduction Project (0704-0188), Washington, DC 20503.

\begin{tabular}{|l|c|c|}
\hline 1. AGENCY USE ONLY (Leave blank) & $\begin{array}{c}\text { 2. REPORT DATE } \\
\text { June } 1998\end{array}$ & $\begin{array}{c}\text { 3. REPORT TYPE AND DATES COVERED } \\
\text { Technical Memorandum }\end{array}$
\end{tabular}

\section{TITLE AND SUBTITLE}

5. FUNDING NUMBERS

Experimental Investigation of Boundary Layer Behavior in a Simulated Low

Pressure Turbine

\section{AUTHOR(S)}

Ki-Hyeon Sohn, Rickey J. Shyne, and Kenneth J. DeWitt

\section{PERFORMING ORGANIZATION NAME(S) AND ADDRESS(ES)}

National Aeronautics and Space Administration

Lewis Research Center

Cleveland, Ohio 44135-3191

WU-523-26-33-00

\section{SPONSORING/MONITORING AGENCY NAME(S) AND ADDRESS(ES)}

National Aeronautics and Space Administration

Washington, DC 20546-0001

8. PERFORMING ORGANIZATION REPORT NUMBER

E-11204

10. SPONSORING/MONITORING AGENCY REPORT NUMBER

NASA TM-1998-207921

\section{SUPPLEMENTARY NOTES}

Prepared for the Turbo Expo 1998 sponsored by the International Gas Turbine Institute of The American Society of Mechanical Engineers, Stockholm, Sweden, June 2-5, 1998. Ki-Hyeon Sohn and Kenneth J. DeWitt, University of Toledo, Toledo, Ohio 43606; Rickey J. Shyne, NASA Lewis Research Center. Responsible person, Rickey J. Shyne, organization code 5820, (216) 433-3595.

12a. DISTRIBUTION/AVAILABILITY STATEMENT

12b. DISTRIBUTION CODE

Unclassified - Unlimited

Subject Categories: 02 and 07

Distribution: Nonstandard

This publication is available from the NASA Center for AeroSpace Information, (301) 621-0390.

13. ABSTRACT (Maximum 200 words)

A detailed investigation of the flow physics occurring on the suction side of a simulated Low Pressure Turbine (LPT) blade was performed. A contoured upper wall was designed to simulate the pressure distribution of an actual LPT blade onto a flat plate. The experiments were carried out at Reynolds numbers of 100,000 and 250,000 with three levels of freestream turbulence. The main emphasis in this paper is placed on flow field surveys performed at a Reynolds number of 100,000 with levels of freestream turbulence ranging from $0.8 \%$ to $3 \%$. Smoke-wire flow visualization data was used to confirm that the boundary layer was separated and formed a bubble. The transition process over the separated flow region is observed to be similar to a laminar free shear layer flow with the formation of a large coherent eddy structure. For each condition, the locations defining the separation bubble were determined by careful examination of pressure and mean velocity profile data. Transition onset location and length determined from intermitten'cy profiles decrease as freestream turbulence levels increase. Additionally, the length and height of the laminar separation bubbles were observed to be inversely proportional to the levels of freestream turbulence.

\begin{tabular}{|c|c|c|c|}
\hline \multicolumn{3}{|c|}{ Low-pressure turbine; Boundary layer; Experiment } & $\begin{array}{c}\text { 15. NUMBER OF PAGES } \\
14 \\
\end{array}$ \\
\hline
\end{tabular}

